Received Date : 02-Jun-2016

Revised Date : 12-Jul-2016

Accepted Date : 18-Jul-2016

Article type : Short Report

r.

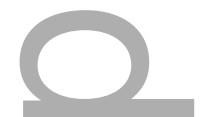

Long-term survival of patients with mismatch repair-deficient, highstage ovarian clear cell carcinoma

${ }^{1,2}$ Colin JR Stewart, ${ }^{3,4}$ David DL Bowtell, ${ }^{2}$ Dorota A Doherty, ${ }^{2,5}$ Yee C Leung.

${ }^{1}$ Department of Pathology, King Edward Memorial Hospital, Perth, Western Australia, ${ }^{2}$ School for Women's and Infants' Health, University of Western Australia, ${ }^{3}$ Peter MacCallum Cancer Centre, East Melbourne, Victoria 3002, Australia, ${ }^{4}$ Department of Biochemistry and Molecular Biology, University of Melbourne, Parkville, Vietoria 3052, Australia, and ${ }^{5}$ Department of Gynaecological Oncology, King Edward Memorial Hospital, Perth, Western Australia.

Running title: MMR protein-deficient clear cell carcinoma

Keywords: ovary, clear cell carcinoma, prognosis, stage, Lynch syndrome

\title{
Correspondence:
}

Dr C Stewart, Department of Histopathology, King Edward Memorial Hospital, Bagot Road, Perth, Western Australia 6008.

Telephone: 0893402715

Fax: 0893402636

Email: colin.stewart@health.wa.gov.au

This is the author manuscript accepted for publication and has undergone full peer review but has not been through the copyediting, typesetting, pagination and proofreading process, which may lead to differences between this version and the Version of Record. Please cite this article as doi: 10.1111/HIS.13040

This article is protected by copyright. All rights reserved 


\begin{abstract}
Aims: Gynaecological cancer patients with germline mutations appear to have a better prognosis than those with sporadic malignancies. Following the observation of longterm survival in a patient with stage III ovarian clear cell carcinoma (CCC) and possible Lynch syndrome (LS), DNA mismatch repair (MMR) protein immunohistochemistry was performed in a series of high-stage CCC and correlated with patient outcomes.
\end{abstract}

Methods and Results: Thirty-two consecutive cases of stage III/ IV ovarian CCCs accessioned between 1992 and 2015 were examined. The tumours from two patients (6\%), including the index case, showed loss of MSH2/MSH6 expression while MLH1/PMS2 staining was retained. The index patient subsequently developed colonic and rectal carcinomas that were also MSH2/MSH6 deficient while the second patient had a genetically confirmed germline $M S H 2$ mutation. All other tumours showed retained expression of the four MMR proteins. The two patients with MMR protein-deficient tumours were alive 160 months and 124 months following surgery whereas the median survival of patients with MMR protein-intact CCCs was 11.8 months $\left(75^{\text {th }}\right.$ and $25^{\text {th }}$ percentiles of 8.1 months and 39.3 months, respectively), with 21 patients deceased due to tumour.

Conclusions: Larger studies are required but high-stage, MMR protein-deficient CCCs may have a relatively favourable prognosis.

\title{
INTRODUCTION
}

Five major subtypes of tubo-ovarian adenocarcinoma are recognised comprising highgrade serous carcinoma, low-grade serous carcinoma, mucinous carcinoma, endometrioid carcinoma (EC) and clear cell carcinoma (CCC). The latter two tumours each account for approximately $10 \%$ of ovarian cancers in Western countries but CCC is relatively common in the Japanese population accounting for up to one quarter of cases (1). Ovarian CCC is often associated with endometriosis and demonstrates distinctive molecular alterations including frequent ARIDIA and PIK3CA mutations, findings that may become important as specific targeted therapies are developed $(1,2)$. 
In recent years it has been appreciated that patients with Lynch syndrome (LS), due to germline mutations in genes encoding for the DNA mismatch repair (MMR) proteins MLH1, PMS2, MSH2 or MSH6, have an increased risk (approximately 10\%) of developing ovarian neoplasia and the majority of these tumours are ECs or CCCs (3). Therefore reflex immunohistochemistry for MMR proteins has been proposed in these cases (4-6).

Traditionally, ovarian CCC has been considered a clinically aggressive malignancy and therefore regarded as high-grade for management purposes. However, the prognosis of surgically staged CCC confined to the ovary is relatively favourable with 5-year survival rates of $80-90 \%$, although the prognosis of stage IC tumours with ovarian capsular involvement and/ or positive peritoneal fluid cytology is more guarded (7-9). High-stage CCCs with lymph node, omental, peritoneal and/or distant metastases have been reported to have a very poor prognosis with inferior survival rates compared to equivalent stage high-grade serous carcinomas $(1,8,10)$. This may partly reflect the relative insensitivity of CCC to standard chemotherapy. In routine practice we identified a possible LS patient with stage III ovarian CCC who had surprisingly long disease-free survival leading us to speculate whether LS-associated CCC might have a better prognosis than sporadic CCC, analogous to findings in colorectal carcinoma where tumours demonstrating MMR protein deficiency and/or microsatellite instability (MSI) have relatively favourable outcomes $(11,12)$. Therefore in the present study we reviewed all high-stage ( $\geq$ stage III) CCCs presenting in our department over a 24-year period (1992-2015), correlating the findings with MMR protein expression and clinical outcomes. The study was performed according to the Declaration of Helsinki and received institutional ethics approval (KEMH reference 11014, 1/2/2016).

\section{CASES AND RESULTS}

A total of 32 patients with high-stage ovarian CCC were identified in the study period. Twenty-nine patients had stage III carcinomas based upon the presence of omental, pelvic and/or para-aortic lymph node metastases while 3 patients had stage IV disease based upon cytologically confirmed malignant pleural effusions (2 cases) or cervical lymph node metastases ( 1 case). All stage IV cases also had omental and/or abdominal lymph node involvement. Immunohistochemistry was performed on representative full face sections of each tumour as previously described with 
appropriate internal positive control staining in all cases (13). Two CCCs (6.3\%), summarised below, demonstrated loss of MSH2/MSH6 staining with preserved MLH1/PMS2 expression (Figure 1). All other tumours showed retained expression of all four MMR proteins.

\section{Mismatch repair protein-deficient $\operatorname{CCCs}(n=2)$}

Case1 (index case)

A 41-year-old underwent simple hysterectomy for menorrhagia. The uterus showed benign appearances but a nodule was noted in the pouch of Douglas intraoperatively and biopsy reyealed CCC. She then underwent bilateral salpingo-oophorectomy, omentectomy and bilateral pelvic lymph node dissection. Both ovaries revealed clear cell carcinoma, the larger right ovarian tumour being up to $25 \mathrm{~mm}$ diameter. The tumour had solid and glandular growth patterns and there was a prominent peritumoural lymphoplasmacytic infiltrate (Figure 1). Endometriosis was not identified. Metastatic CCC was present in 1/5 left external iliac lymph nodes but there was no evidence of metastasis in the omentum or in 87 additional pelvic nodes, and peritoneal fluid cytology was also negative. The patient received adjuvant pelvic radiotherapy. Thirteen years later she underwent surgery for concurrent mucinous carcinoma of the sigmoid colon and signet ring cell carcinoma of the rectum. Both tumours were confined to the bowel wall (pT2) but metastatic carcinoma (of probable sigmoid origin) was present in 1/16 pericolic nodes. Immunohistochemistry showed loss of MSH2/MSH6 expression in both tumours, similar to the ovarian CCC. The patient had no evidence of tumour recurrence at last known follow-up 160 months after her initial gynaecological surgery.

\section{Case 2}

A 45-year-old presented with a pelvic mass and was found at laparotomy to have bilateral, 6-7cm ovarian tumours and multiple omental tumour deposits measuring up to $15 \mathrm{~mm}$. Histological examination demonstrated bilateral ovarian CCC showing a predominantly solid growth pattern with confirmed omental metastases. There was a relatively mild and focal tumour-associated lymphoplasmacytic infiltrate more prominent in the omentum. Endometriosis was not identified. The uterus showed benign findings and peritoneal fluid cytology was negative. Lymphadenectomy was not performed. Post-operatively the patient received standard platinum-based adjuvant 
chemotherapy. She had a family history of colorectal and ovarian cancer and had undergone multiple screening colonoscopy examinations beginning 5 years prior to her presentation with ovarian neoplasia. On most occasions colonoscopy revealed 1 or 2 polyps which were variably of adenomatous or hyperplastic type but there was no invasive colonic malignancy. Subsequently genetic analysis confirmed LS due to a germline MSH2 mutation. There was no evidence of tumour recurrence at last known follow-up 124 months following her gynaecological surgery.

\section{Mismatch repair protein-intact $\operatorname{CCCs}(\mathbf{n}=30)$}

The median age of the patients was 52 years (range 37-73 years). Nineteen patients (63\%) had histologically documented endometriosis either in the ovary affected by tumour or in other pelvic sites. Omental sampling was performed in all patients and was positive for CCC in 22 cases (73\%) while peritoneal fluid cytology was positive in $21 / 25$ (84\%) patients. Pelvic and/or paraaortic nodal metastases were present in 13/15 patients (87\%) who underwent lymphadenectomy. Follow-up data, available in 29 cases, are summarised in Figure 2. The overall median follow-up interval was 9.6 months (range 0.8-119), with a median of 14.1 months (range 2.5-54.9) for those patients who were disease-free clinically at last follow-up. The median survival was 11.8 months with the $75^{\text {th }}$ and $25^{\text {th }}$ percentiles being 8.1 and 39.3 months, respectively.

\section{DISCUSSION}

Lynch syndrome-associated and MMR protein-deficient ovarian carcinomas are most commonly of clear cell or endometrioid subtype $(5,6,14)$, although, conversely, only $2-14 \%$ of these tumours demonstrate MMR protein deficiency and/or microsatellite instability (MSI) (15-18). The current study, albeit restricted to high-stage CCC specifically, supported these findings since MMR protein-deficiency was identified in only $2 / 32$ tumours $(6.3 \%)$. Interestingly, both of these tumours were bilateral, a generally uncommon finding in ovarian CCC although there are limited data on highstage cases (19). Genetic analysis confirmed the diagnosis of LS in one case but this was not performed in the second patient and therefore it is uncertain whether she had LS or a 'Lynch-like' syndrome which may also be associated with MMR proteindeficient neoplasia $(20,21)$. 
The prognosis of high-stage ovarian CCC is considered very poor and this is illustrated by the present series where 22 of 31 patients (71\%) with follow-up information died of metastases with a median survival of less than 1 year. However, surprisingly long-term survival of at least 124 and 160 months was recorded in the two stage III patients with possible or confirmed LS. Similarly, a LS patient with stage III CCC in the series of Niskakoski et al survived at least 156 months (14). Recently Bennett and colleagues reported MMR protein deficiency in 6/109 unselected ovarian CCC and two of these patients, both with likely LS, had stage III disease (17); one patient (who also had endometrial carcinoma) died of tumour 14 months after diagnosis but the other was disease free at 93 months. These findings, albeit based upon a small number of cases, raise the possibility that high-stage LSassociated and/or MMR protein-deficient ovarian CCCs have a better prognosis than similar stage sporadic tumours. In this regard it is noteworthy that in a multicentre European study of LS-associated ovarian tumours the overall 5-year survival for stage III/IV cases was 59\% compared with an expected survival of approximately 30-35\% in high-stage ovarian carcinoma generally (22). However, this study had limited histological correlation and also included non-epithelial tumours, and therefore correlation with a CCC phenotype is not possible.

Treatment details were not available in most patients in this series and therefore we were unable to determine whether prolonged survival in the two patients with MMR protein-deficient CCCs was associated with a more favourable response to adjuvant therapy. We note that Case 2 was unlikely to have been cured surgically due to the extensiye nature of her disease at presentation. Interestingly, a recent study of endometrial carcinomas found that patients with probable LS and high-stage disease who received adjuvant therapy showed better outcomes (23). Improved survival of LS patients may also apply to those with low-stage CCC but this will be more difficult to determine given the generally favourable outcome in this group of patients. It has been suggested that improved survival in LS-associated carcinomas may be due to the diploid nature of these tumours, reduced tumour viability due to genomic instability, and/or the prominent immune reaction that often characterises such cases (24). In regard to the latter, it is noteworthy that the one of the CCCs presented herein was associated with a prominent lymphoplasmacytic infiltrate.

In summary, we describe two patients with possible/ confirmed LS and longterm survival following the diagnosis of stage III ovarian CCC. While larger studies 
are required, these findings raise the possibility that MMR protein-deficient CCCs have a relatively favourable prognosis, analogous to colorectal carcinoma.

\section{ACKNOWLEDGEMENT}

The authors are most grateful to colleagues for providing clinical follow-up data and access to tumour material for immunohistochemistry. Authors CJRS, DDLB and YCL were involved in designing the study, CJRS drafted the manuscript and DAD performed the statistical analysis. All authors helped to prepare and approved the final manuscript.

\section{REFERENCES}

1. Okamoto A, Glasspool RM, Mabuchi S, et al. Gynecologic Cancer Intergroup (GCIG) consensus review for clear cell carcinoma of the ovary. Int J Gynecol Cancer 2014;24:S20-25.

2. Tan DSP, Miller RE, Kaye SB. New perspectives on molecular targeted therapy in ovarian clear cell carcinoma. B J Cancer 2013;108:1553-1559.

3. Folkins AK, Longacre TA. Hereditary gynaecological malignancies: advances in screening and treatment. Histopathology 2013;62:2-30.

4. Chui MH, Gilks CB, Cooper K, Clarke BA. Identifying Lynch syndrome in patients with ovarian carcinoma: the significance of tumor subtype. Adv Anat Pathol 2013;20:378-386.

5. Chui MH, Ryan P, Radigan J, et al. The histomorphology of Lynch-syndromeassociated ovarian carcinomas: towards a subtype-specific screening strategy. Am J Surg Pathol 2014;38:1173-1181.

6. Rambau PF, Duggan MA, Ghatage P, et al. Significant frequency of MSH2/MSH6 abnormality in ovarian endometrioid carcinoma supports a histiotype-specific Lynch syndrome screening in ovarian carcinomas. Histopathology 2016;69:288-297.

7. Hoskins PJ, Le N, Gilks B, et al. Low-stage ovarian clear cell carcinoma: population-based outcomes in British Columbia, Canada, with evidence for a survival benefit as a result of irradiation. J Clin Oncol 2012;30:1656-1662.

8. Tan DSP, Kaye S. Ovarian clear cell adenocarcinoma: a continuing enigma. J Clin Pathol 2007;60:355-360.

9. Shu CA, Zhou Q, Jotwani AR, et al. Ovarian clear cell carcinoma, outcomes by stage: the MSK experience. Gynecol Oncol 2015;139:236-241. 
10. Sugiyama T, Kamura T, Kigawa J, et al. Clinical characteristics of clear cell carcinoma of the ovary. Cancer 2000;88:2584-2589.

11. Popat S, Hubner R, Houlston RS. Systematic review of micro-satellite instability and colorectal cancer prognosis. J Clin Oncol 2005;23:609-618.

12. Bellizzi AM. Contributions of molecular analysis to the diagnosis and treatment of gastrointestinal neoplasms. Semin Diagn Pathol 2013;30:329-361.

13. Stewart CJR, Crook ML. SWI/SNF complex deficiency and mismatch repair protein expression in undifferentiated and dedifferentiated endometrial carcinoma. Pathology 2015;47:439-445.

14. Niskakoski A, Kaur S, Renkonen-Sinsalo L, et al. Distinct molecular profiles in Lynch syndrome-associated and sporadic ovarian carcinomas. Int J Cancer 2013;133:2596-2608.

15. Vierkoetter KR, Ayabe AR, VanDrunen M, Ahn HJ, Shimuzu DM, Terada KY. Lynch syndrome in patients with clear cell and endometrioid cancers of the ovary. Gynecol Oncol 2014;135:81-84.

16. Cai KQ, Albarracin C, Rosen D, et al. Microsatellite instability and alteration of the expression of hMLH1 and hMSH2 in ovarian clear cell carcinoma. Hum Pathol 2004;35:552-559.

17. Bennett JA, Morales-Oyarvide V, Campbell S, Longacre TA, Oliva E. Mismatch repair protein expression in clear cell carcinoma of the ovary: incidence and morphologic associations in 109 cases. Am J Surg Pathol 2016;40:656-63.

18. Stewart CJR, Walsh MD, Budgeon CA, Crook ML, Buchanan DB. Immunophenotypic analysis of ovarian endometrioid adenocarcinoma: correlation with KRAS mutation and the presence of endometriosis. Pathology 2013;45:559-566. 19. Clement PB, Young RH. Surface epithelial-stromal tumors: endometrioid, clear cell, transitional, squamous, rare, undifferentiated, and mixed cell types. In Clement PB and Young RH eds. Atlas of Gynecologic Surgical Pathology, $3^{\text {rd }}$ edition. London: Elsevier Saunders, 2014;380-407.

20. Mills AM, Longacre TA. Lynch syndrome screening in the gynecologic tract. Current state of the art. Am J Surg Pathol 2016;40:e35-e44.

21. Buchanan DD, Rosty C, Clendenning M, Spurdle AB, Win AK. Clinical problems of colorectal cancer and endometrial cancer cases with unknown cause of mismatch repair deficiency (suspected Lynch syndrome). Appl Clin Genet 2014;7:183-193. 
22. Grindedal EM, Renkonen-Sinisalo L, Vasen H, et al. Survival in women with

MMR mutations and ovarian cancer: a multicentre study in Lynch syndrome kindreds.

J Med Genet 2010;47:99-102.

23. Shikama A, Minaguchi T, Matsumoto K, et al. Clinicopathologic implications of DNA mismatch repair status in endometrial carcinomas. Gynecol Oncol 2016;140:226-233.

24. Drescher KM, Sharma P, Lynch HT. Current hypotheses on how microsateallite instability leads to enhanced survival of Lynch syndrome patients. Clin Devel Immunol 2010.doi:10.1155/2010/170432.

\section{FIGURE LEGENDS}

Figure 1. Case 1. A. Ovarian clear cell carcinoma. The tumour is associated with a prominent lymphoplasmacytic infiltrate. B. Higher magnification showing solid and glandular architecture. Part of a follicular cyst is present at upper right. Imuunohistochemistry on corresponding sections shows retained expression of MLH1 (C) but loss of MSH2 (D) in the tumour cells (insets at high magnification).

Figure 2. Survival curve of mismatch repair protein-intact, high-stage ovarian clear cell carcinomas.

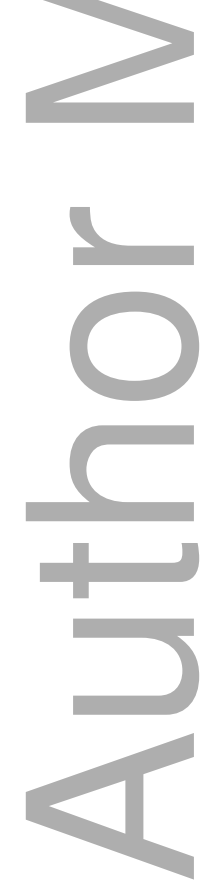

This article is protected by copyright. All rights reserved 


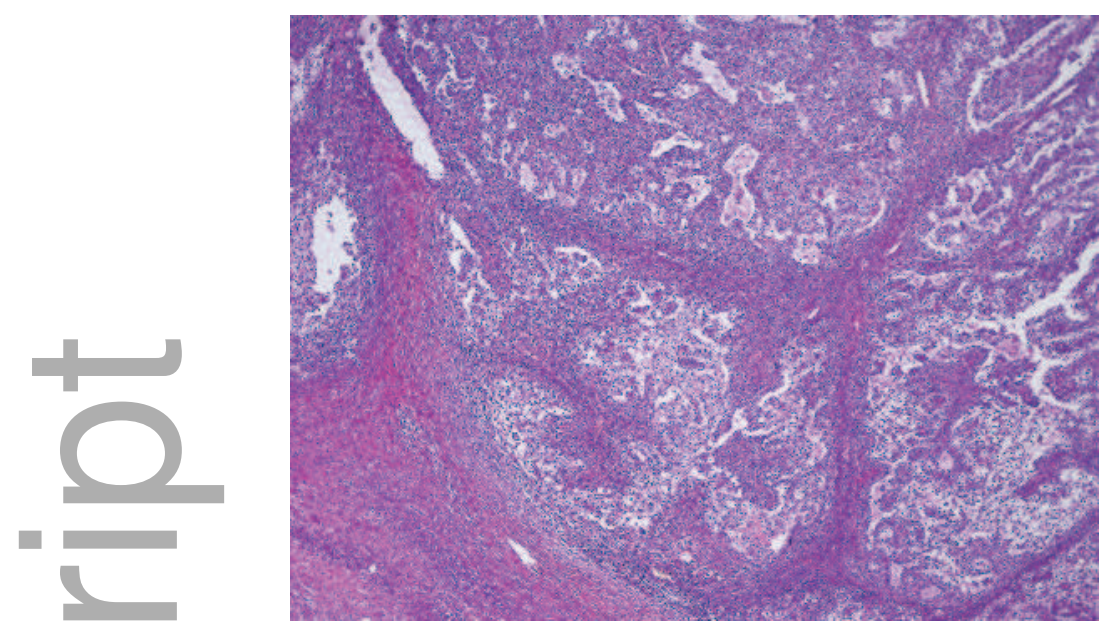

his_13040_f1a.tif
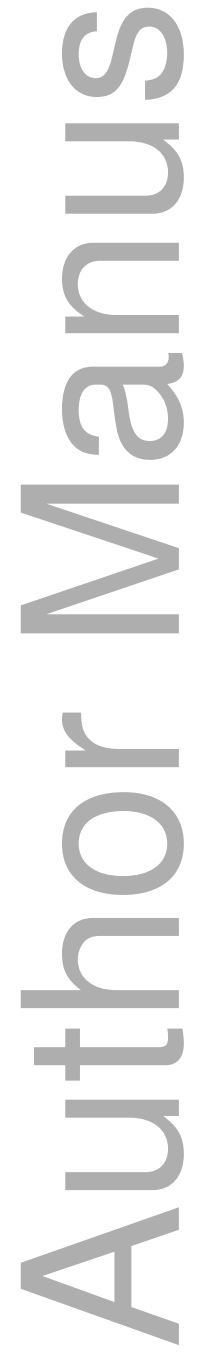

This article is protected by copyright. All rights reserved 


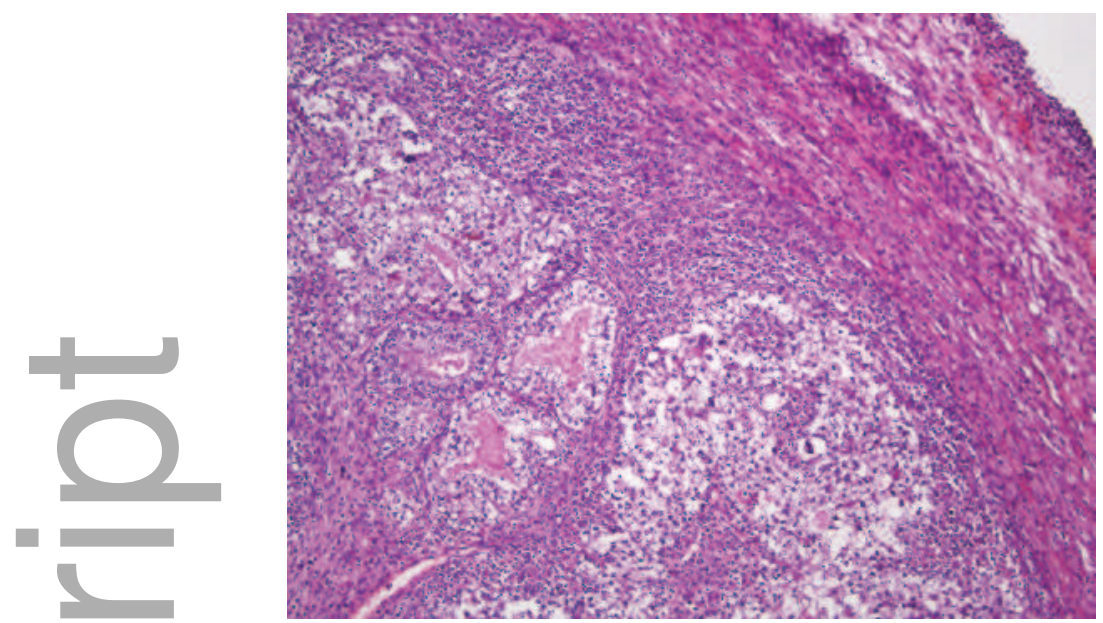

his_13040_f1b.tif
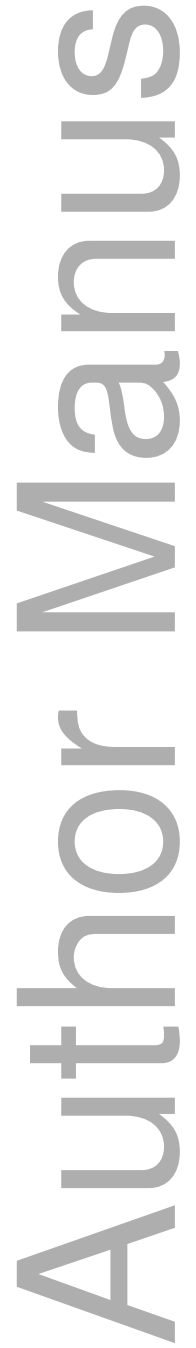

This article is protected by copyright. All rights reserved 


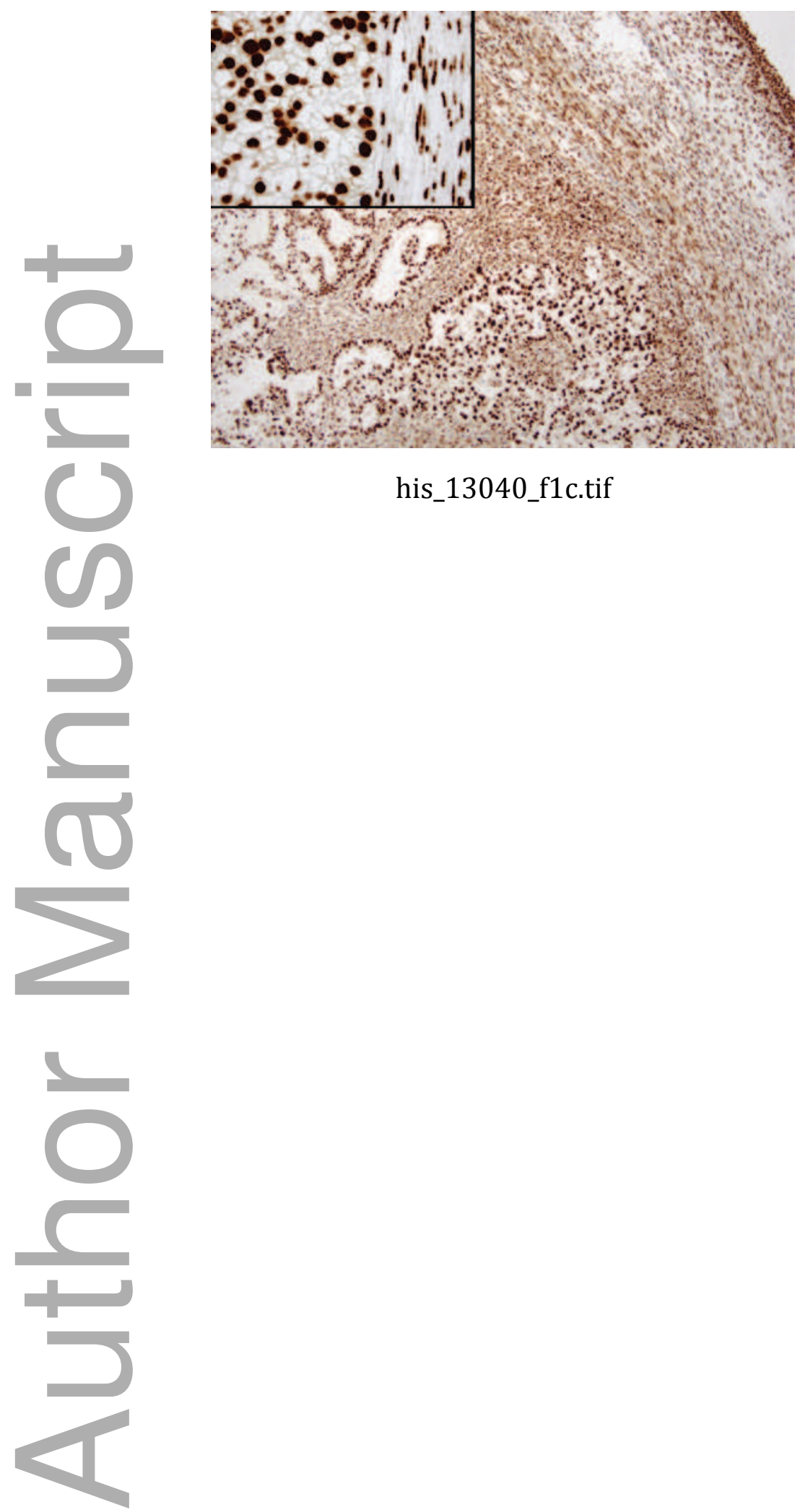

This article is protected by copyright. All rights reserved 


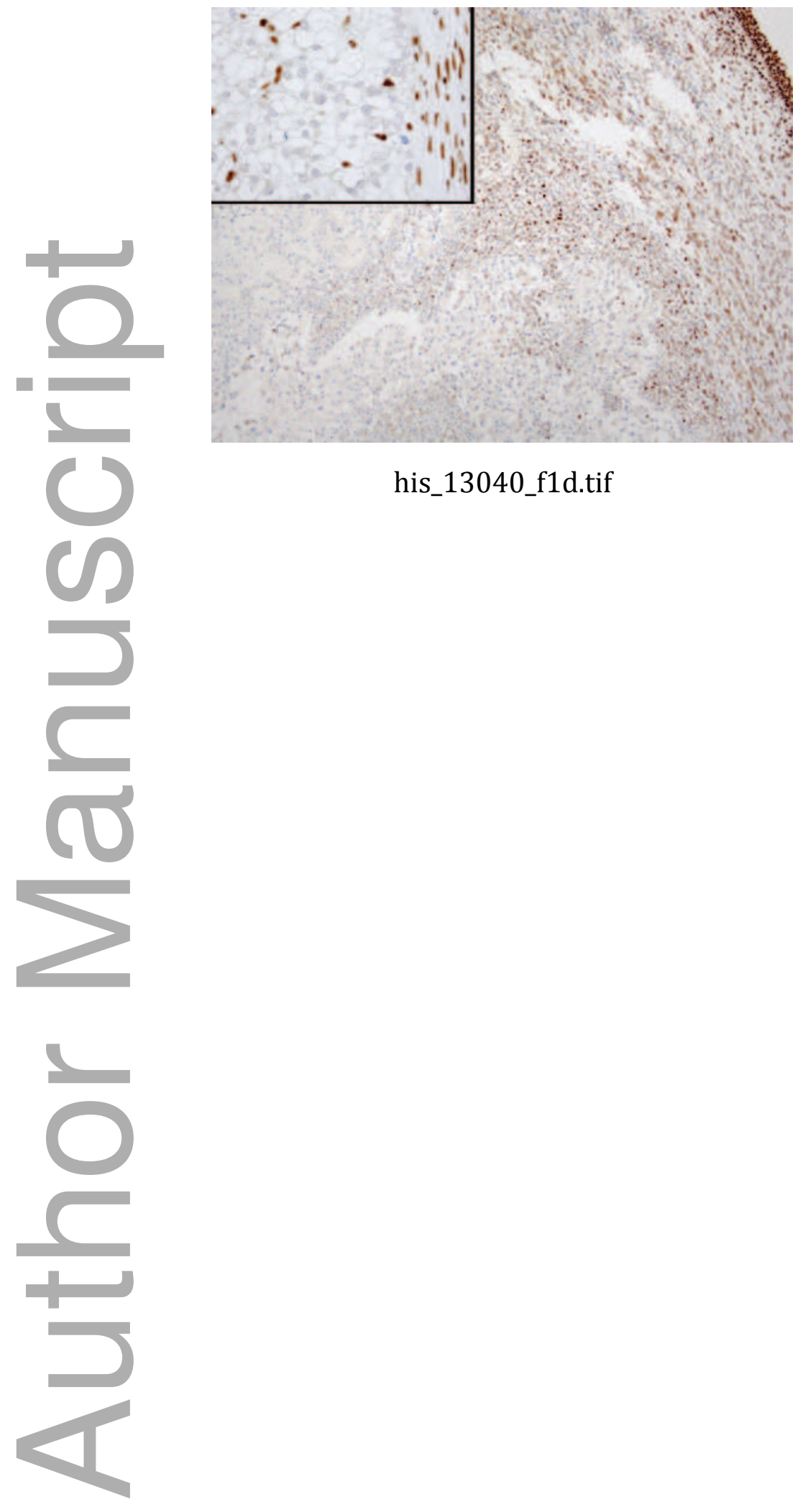

This article is protected by copyright. All rights reserved 


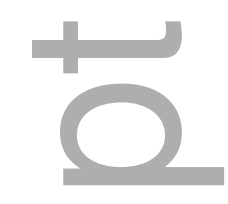

$\square$
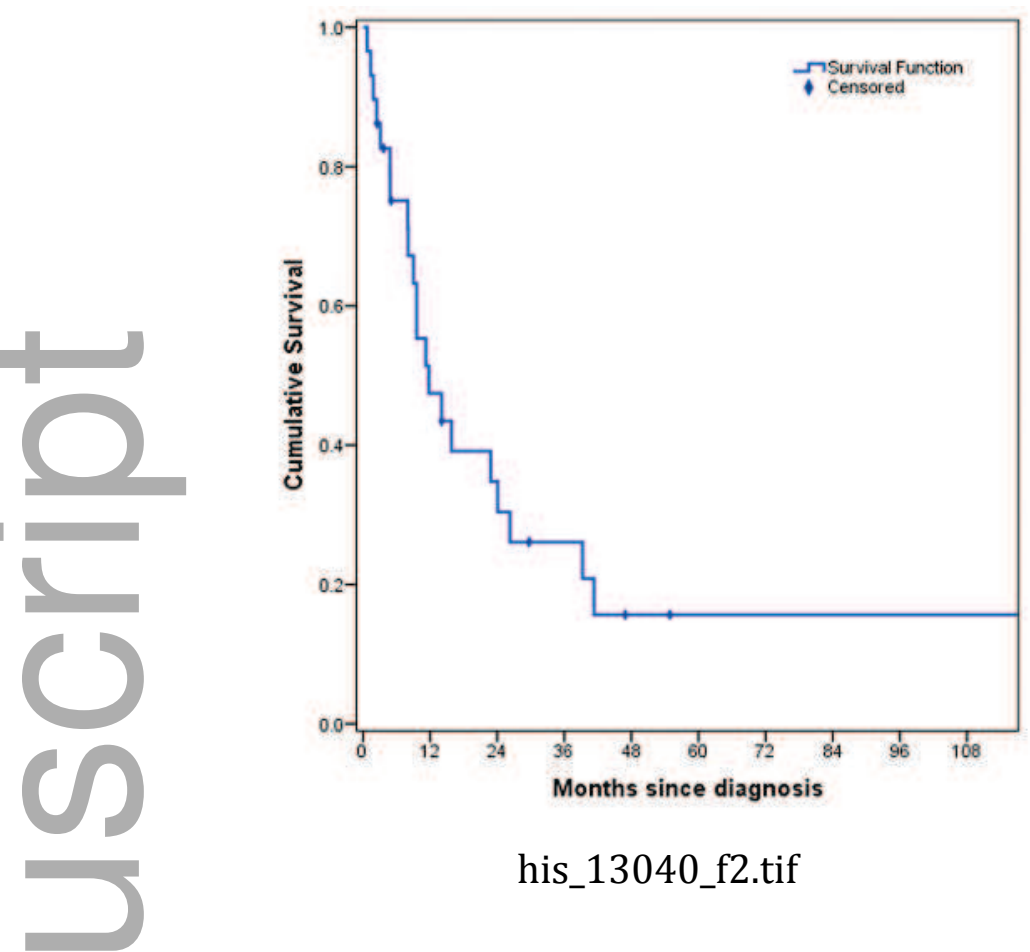

his_13040_f2.tif
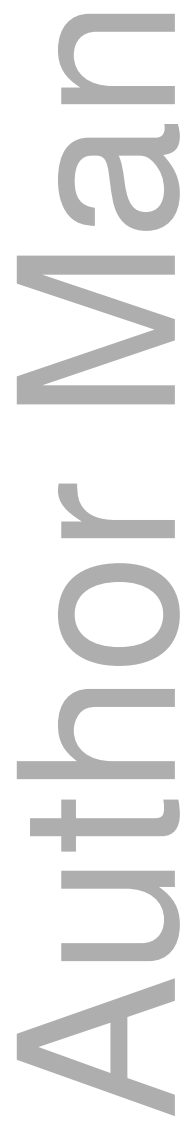

This article is protected by copyright. All rights reserved 


\section{University Library}

\section{- M M N E R VA A gateway to Melbourne's research publications}

Minerva Access is the Institutional Repository of The University of Melbourne

Author/s:

Stewart, CJR;Bowtell, DDL;Doherty, DA;Leung, YC

Title:

Long-term survival of patients with mismatch repair protein-deficient, high-stage ovarian clear cell carcinoma

Date:

2017-01-01

Citation:

Stewart, C. J. R., Bowtell, D. D. L., Doherty, D. A. \& Leung, Y. C. (2017). Long-term survival of patients with mismatch repair protein-deficient, high-stage ovarian clear cell carcinoma. HISTOPATHOLOGY, 70 (2), pp.309-313. https://doi.org/10.1111/his.13040.

Persistent Link:

http://hdl.handle.net/11343/291752 